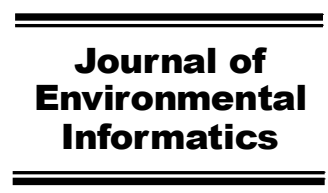

www.iseis.org/jei

\title{
Using High Resolution Images from UAV and Satellite Remote Sensing for Best Management Practice Analyses
}

\author{
B. Yang ${ }^{1,2}$, S. T. Y. Tong ${ }^{2}$, and R. Fan ${ }^{2}$ \\ ${ }^{1}$ Department of Sociology, University of Central Florida, Orlando, Florida 32816, USA \\ ${ }^{2}$ Department of Geography and GIS, University of Cincinnati, Cincinnati, Ohio 45221, USA
}

Received 20 January 2018; revised 15 January 2019; accepted 8 October 2019; published online 13 May 2020

\begin{abstract}
Best Management Practices (BMPs) are commonly adopted to ameliorate the quality of runoff and reduce the frequency and intensity of flash floods in urban areas. To date, many of the BMP studies are conducted using coarse resolution data. However, the accuracy of such studies may be compromised due to the shortcomings inherent in the input data; as such, the evaluation of the BMP cost-effectiveness may not be accurate. The objective of this paper is to demonstrate the improvements of higher resolution images over coarse resolution data in BMP analyses. An unmanned aerial vehicle (UAV) was used to collect a more detailed and accurate picture of the digital surface model and digital elevation model. Landsat 8 multi-spectral imagery was classified by object-oriented classification to generate a land use/land cover map. The method used in this study provided more detailed and accurate information of the physical conditions of the study area, an improved subwatershed delineation, a more comprehensive list of the suitable locations for BMPs, and a more reliable estimate of the cost-effectiveness of the BMP ensembles than that generated using coarse resolution data. Using the fine resolution data, this study further determined the utility of the selected BMP ensembles under a changed future climate regime and identified the best BMP and BMP ensemble in reducing urban surface runoff. This method can be especially useful in areas without quality topography and land use data.
\end{abstract}

Keywords: BMPs, Landsat 8, object-oriented classification, SUSTAIN, UAV, watershed management

\section{Introduction}

Urban Best Management Practices (BMPs) are structural facilities designed to mitigate stormwater runoff (Liu et al., 2017). To effectively control the quantity of surface runoff, one needs to conduct accurate analyses so as to design appropriate BMPs. To this end, high quality aerial photographs and digital elevation model (DEM) are indispensable. A typical satellite remote sensing system, such as the Landsat, ASTER, AVHRR, and MODIS, has a relatively coarse resolution of 10 to $30 \mathrm{~m}$ (Tucker, 1979; Kerr and Ostrovsky, 2003), while the use of imagery sensors mounted on unmanned aerial vehicles (UAVs) can provide imageries with a finer resolution (sub-meter) and more accurate information. It is also less expensive and more convenient to acquire data using UAVs than manned aircrafts, especially for inaccessible places. Although satellites can capture imageries of remote areas and difficult terrain, they have rigid temporal revisit cycles. UAVs, on the other hand, can collect real-time on-demand data. For these reasons, UAV technology has been developing rapidly, and there have been many research projects employing UAVs to collect hyperspectral

${ }^{*}$ Corresponding author. Tel.: +(1) 513556 3435; fax: +(1) 5135563370. E-mail address: susanna.tong@uc.edu (S. T. Y. Tong).

ISSN: $1726-2135$ print/1684-8799 online

(C) 2020 ISEIS All rights reserved. doi:10.3808/jei.202000433.
(Mitchell et al., 2012; Uto et al., 2013) and thermal data (Berni et al., 2009; Zarco-Tejada et al., 2012). Some researchers also used LiDAR sensors mounted on drones to collect elevation data and develop DEMs (Rock et al., 2011; Harvey et al., 2014; Uysal et al., 2015). Nevertheless, there is little research on the benefits of using finer resolution data in watershed management, although sustainable development is becoming a more and more important issue in light of future climate change and urbanization.

The use of finer resolution data is particularly advantageous in BMP studies because many urban BMPs, such as infiltration trenches and bioretention systems, are rather small and are installed in local sites. Also, due to the complicated physical and environmental conditions intrinsic in a watershed, there can be multiple possibilities for the types, number, placements, and combinations of BMPs. However, limited resources often confine BMP implementations to only those that can yield maximum runoff reductions at minimum costs. We therefore need data that can support more detailed analyses in a site scale.

The study described herein is a continuation of an earlier study by Fan et al. (2017), which examined the cost-effectiveness of different arrangements of BMPs in the Ludlow watershed in Kenton County, northern Kentucky (Figure 1). It employed data from secondary sources, such as the national data archives from the U.S. Geological Survey (USGS) and the Multi-resolution Land Characteristics Consortium (MRLC). 
The spatial scales of the DEM and the 2006 land use/land cover (LULC) data are $30 \mathrm{~m}$. That study found that bioretention and infiltration trenches are the most appropriate BMPs in the study area according to soil type, topography, and available surface area required for BMP installation. It further identified three suitable sites for their installation. Because of the dated (2006) LULC information and the relatively coarser resolutions in both the DEM and LULC data, the results might not reflect the potential environmental benefits and associated costs of these BMPs.

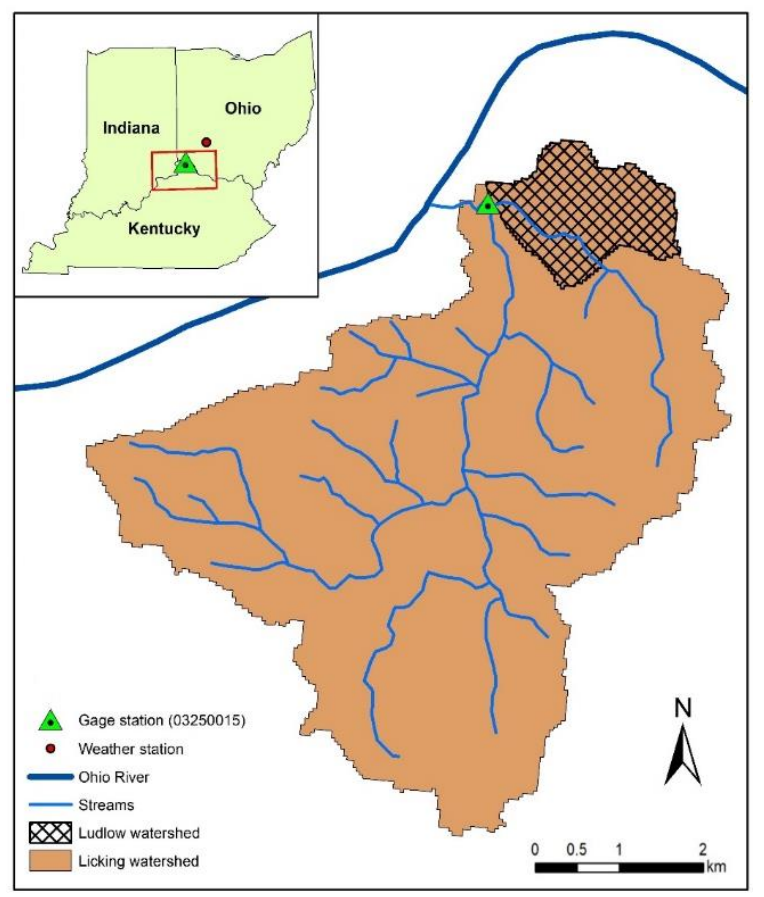

Figure 1. Map showing the Ludlow watershed study area.

In this research, we used UAV techniques to collect DEM data at a higher spatial resolution for the same study area. Meanwhile, Ground Control Point (GCPs) were collected in the study area to rectify and validate the DEM. We also acquired the new Landsat 8 multi-spectral remote sensing imagery and utilized the object-oriented classification method to generate a more detailed and updated (2016) LULC dataset. The main objective was to examine how finer resolution data would facilitate a more comprehensive watershed BMP analysis. To this end, we derived two BMP scenarios. The three-BMP-ensemble, which had the same number and types of BMPs as in Fan et al. (2017), was used to explore how better subwatershed delineation and BMP siting could improve BMP simulation results. The sevenBMP-ensemble depicted the maximum number of BMPs that could be installed in the watershed, an arrangement that would only be made possible by the better quality data. This analysis was to determine the maximum potential annual flow reduction and the associated costs.

While there are reports on the use of BMPs in urban watershed management (see for example, Snead and Maidment, 2000), there is hardly any reference of their use in watersheds with mixed land use, such as the Ludlow watershed. Therefore, the other objectives of this research were to assess the utilities (costs and benefits) of the BMP ensembles and to determine the future efficacy of the selected BMP ensembles in attenuating surface runoff in such a watershed.

\section{Study Area and Data Processing}

\subsection{Study Area}

We used the same Ludlow watershed as our study area (Figure 1). Its area is $1.24 \mathrm{~km}^{2}$ and its population has been growing since World War II. The city of Ludlow is redeveloping, and highly developed area now occupies about $46.64 \%$ of the watershed, whereas medium intensity developed area covers $27.27 \%$ of the watershed (Fry et al., 2011; Wickham and Flather, 2013). With recent urban development, sustainable watershed management schemes are needed. By providing a more accurate picture of the land use types and physical conditions of the area, the UAV and remote sensing data may be helpful in this endeavor.

The climate of northern Kentucky is cool and wet. Its average daily temperature varies from 17 to $31^{\circ} \mathrm{C}$ during summer and from -5 to $12{ }^{\circ} \mathrm{C}$ during winter. Winter and spring precipitations are usually in the form of low intensity events over a longtime period, while summer precipitations are characterized by high-intensity and short-duration storms (NCDC, 2012).

The Ludlow watershed was chosen in this study because to make a fair comparison with the previous study, it is more appropriate to use the same study area. Most importantly, it is frequently flooded. The Ohio River is a mighty river. Its large volume of water and high stream velocities have carved deep valleys with extraordinarily steep gradients around the study region. The narrow flood plains and intensive urban development have caused frequent flooding in low-lying regions, and the economic damages are staggering. It is therefore paramount to mitigate floods as the watershed is urbanizing and our climate is changing with probably more intense storm events. Installation of proper BMPs may be instrumental in controlling stormwater (U.S. Federal Insurance Administration, 1979).

\subsection{Data Acquisition and Processing}

\subsubsection{Acquisition of High Resolution UAV and Remote Sensing Data}

UAV offers data of higher quality with a finer spatial resolution than most of the products from available satellites. The cost to deploy an UAV is also lower than data acquired from LiDAR sensor installed on manned aircraft. Listed in Table 1 are three examples of UAV and customized camera combinations as well as the rental fees to charter a manned aircraft for collecting and producing multi-spectral imagery, digital surface model (DSM), DEM, and orthomosaics.

Data collection by UAVs has many advantages. Battery powered UAV has less environmental impacts than aircrafts powered by fossil fuels. UAVs are more convenient and easier to launch. 
Table 1. Comparison between Costs for Customized UAV and Manned Aircrafts

\begin{tabular}{|c|c|c|c|}
\hline \multicolumn{4}{|c|}{ UAV and camera solutions } \\
\hline & $\begin{array}{l}\text { DJI phantom } 4 \text { Pro } \\
\text { + stock camera }\end{array}$ & $\begin{array}{l}\text { 3DR SOLO } \\
+ \text { MAPIR cameras }\end{array}$ & $\begin{array}{l}\text { DJI MATRICE } 100 \\
+ \text { FLIR VUE PRO }\end{array}$ \\
\hline UAV cost & $\$ 1,599 \sim 2,499$ & $\$ 700 \sim 2,200$ & $\$ 3,299 \sim 8,399$ \\
\hline Camera cost & Included & $\$ 300 \sim 1,200$ & $\$ 1,499 \sim 4,499$ \\
\hline Fly time & 28 minutes & 21 minutes & 42 minutes \\
\hline Payload & $600 \mathrm{~g}$ & $500 \mathrm{~g}$ & $1,000 \mathrm{~g}$ \\
\hline \multicolumn{4}{|c|}{ Manned aircraft and rental rates* } \\
\hline & Very light jet & Light jet & Executive Turboprop \\
\hline Aircraft example & $\begin{array}{l}\text { Phenom 100, } \\
\text { Eclipse } 500\end{array}$ & $\begin{array}{l}\text { Hawker 400XP, } \\
\text { Learjet 31A }\end{array}$ & $\begin{array}{l}\text { King Air 200, Air 90, } \\
\text { Pilatus PC-12 }\end{array}$ \\
\hline Rental rate (h) & $\$ 1,750 \sim 2,200$ & $\$ 2,200 \sim 2,800$ & $\$ 1,500 \sim 1,850$ \\
\hline Number of seats & $2 \sim 4$ & $6 \sim 7$ & $3 \sim 8$ \\
\hline
\end{tabular}

*Rates quoted from NewFlightcharters (2017).

Once UAVs are set up, they can be reused. To deploy a UAV, one only requires some flight training and a FAA part 107 certification, which costs far less than obtaining an aircraft pilot license. UAV is also safer when negotiating inaccessible, difficult, and hazardous terrain. Although a manned aircraft can provide more payloads and a higher fly height than an UAV, data collected by an UAV are sufficient for most local scale environmenttal monitoring and watershed management studies.

In this research, we used DJI Phantom IV Pro quadcopter (Figure 2) (Themistocleous, 2014; Stroppiana et al., 2015) and a stock 1/2.3 inch $(1.10 \mathrm{~cm})$ CMOS camera sensor with a 12.4 $\mathrm{m}$ effective pixels and Field of Vision (FOV) of $94^{\circ} 20 \mathrm{~mm} \mathrm{f} /$ 2.8 focus at $\infty$ (DJI, 2017). The reconnaisances UAV flights over the Ludlow watershed were conducted on April 30, 2017. It was a clear day with good visibility and relatively low wind speed. In UAV data collection, there is a trade-off between UAV flight coverage and the spatial resolution of the image product. Although a higher flying height can provide a larger areal coverage, the spatial resolution of the UAV image will be compromised. To resolve this dilemma, we divided the Ludlow watershed into 3 sub-regions and conducted separate flights for each sub-region (Figure 3). With a flying height of approximately $120 \mathrm{~m}$, the UAV imagery after mosaic has both a high resolution and a full coverage of the study area.
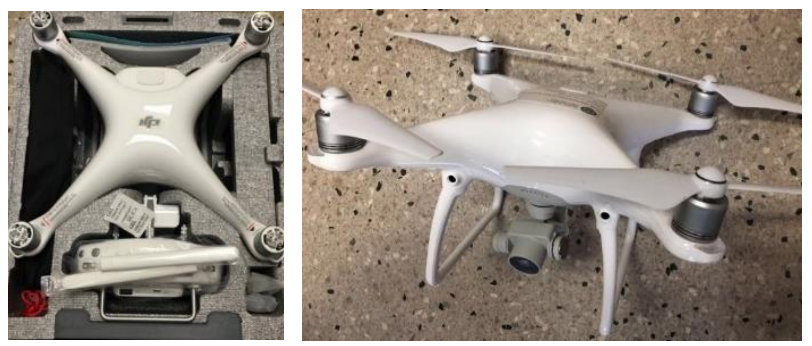

Figure 2. The DJI Phantom IV UAV system used in the present research.

Given that there is a view angle between the drone camera and land objects, to produce DEM/DSM products with a higher accuracy, it is better to capture imagery from all directions and aspects of the target area. Thus, for each flight, our drone followed a route of inscribed circles of the sub-region. Each circle has a radius of approximately $300 \mathrm{~m}$ (Figure 3 ). As such, images taken by the UAV are evenly distributed along the circle and the camera is always pointing to the center of the target area (Figure 4). Elevation distortions due to view angle of the camera can then be rectified during data processing.

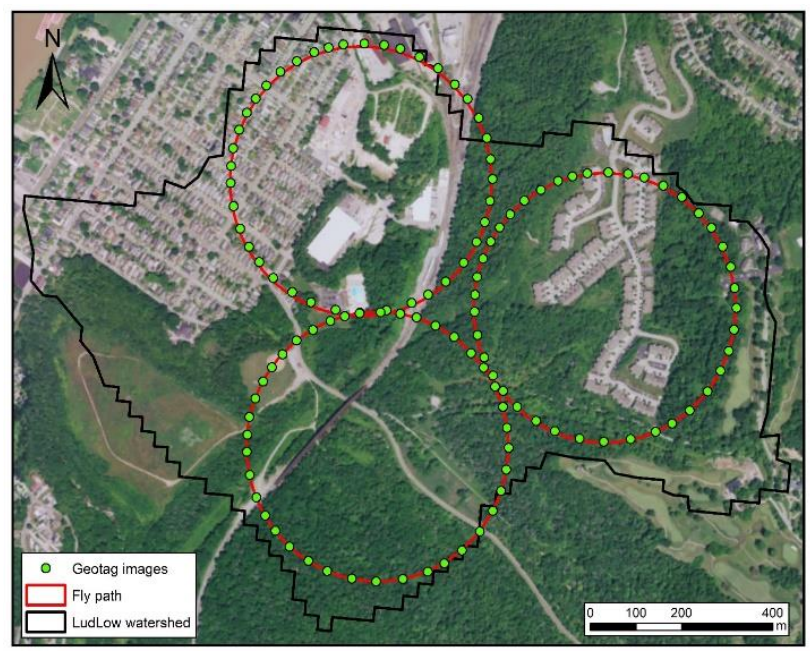

Figure 3. GCPs, fly path, and UAV imagery geotags in the Ludlow watershed.

Based on the flight altitude and pixel size of the UAV imagery, the DSM, DEM, and orthoimages generated in this study have a very high spatial resolution $(0.8 \mathrm{~m})$. Nevertheless, the images only have red, green, and blue bands, which are inadequate to distinguish impervious surfaces. However, impervious surfaces are prevalent in urban areas and have significant hydrologic effects (Slonecker et al., 2001). To resolve this quandary, Landsat 8 remote sensing imagery was incorporated to take advantage of its multi-spectral capability and its near infrared band to depict impervious surfaces. 
The July 12, 2016 Landsat 8 data were acquired from USGS (2017a). They have multi-spectral bands, including blue, green, red, near infrared, shortwave infrared, panchromatic, and thermal infrared, with a $30 \mathrm{~m}$ spatial resolution for the optical bands and a $15 \mathrm{~m}$ spatial resolution for the panchromatic band. In the earlier study, the LULC data were obtained from the National Land Cover Database (NLCD) of the MRLC, which are based primarily on Anderson classification of the 2006 Landsat satellite data (Fry et al., 2011) and are at a $30 \mathrm{~m}$ resolution. Here, due to the higher spatial resolution and the more sophisticated object-orientated classification algorithm used in the classification, the resultant LULC coverage has more updated and reliable information (Figure 5).

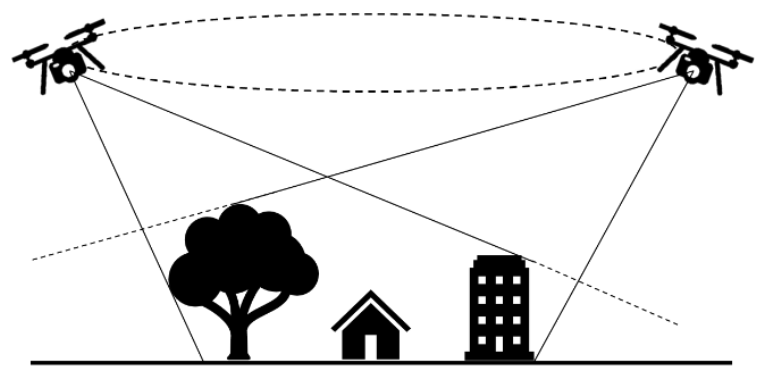

Figure 4. UAV circle fly path around the target area.

\subsubsection{DEM Data Processing}

The image captured by the stock camera on-board the UAV was transformed via the Drone2Map software (ESRI, 2017) into professional 2D and 3D products, including orthoimages, DSM, DEM, cloud points, and Normalized Difference Vegetation Index (NDVI).

The UAV DEM for the entire study area was obtained by mosaicing the images of the three sub-regions (Figure 6a). To calibrate the DEM and rectify the UAV imagery, 26 GCPs were collected from easily discernable land features, such as road intersections and corners of playgrounds, in the Ludlow watershed (Figure 3) using the Trimble high-performance GNSS System, which has the capability of measuring and recording the geographical coordinates with an accuracy of less than $0.5 \mathrm{~m}$. After calibration, a quality DEM was generated from the UAV imagery (Figure 6a) via Drone2Map software. To ascertain its accuracy, the UAV DEM was validated against the USGS DEM data from the National Elevation Dataset (NED) (USGS, 2015) (Figure 6b). Because the USGS DEM data have a spatial resolution of $30 \mathrm{~m}$, some reference targets, such as parking lots and golf courses, were used in the validation. The results show that the UAV DEM had an estimated elevation accuracy of $1.3 \mathrm{~m}$.

\subsubsection{Derivation of Land Use Data by Object-Oriented Classification of Landsat Data}

Object-oriented classification is based on the relationships between image objects, which are derived from dividing the whole image into small objects according to the shape, size, and spectral content of the image segments. Because objectoriented classification generates classes at object level, with ap- propriate training samples and parameters, it has an excellent capability to delineate objects at a local scale (Jacquin et al., 2008). When compared with traditional pixel-based classification methods, which use regular pixels, object-oriented classifycation is more appropriate for hydrologic modeling of small urban watersheds (Li et al., 2014). Thus, it has been widely used for automatic and semiautomatic analyses (Benz et al., 2004; Liu et al., 2010; Zhang et al., 2014).

We performed the object-oriented classification on the Landsat 8 multi-spectral data using eCognition (Trimble, 2017). Multiresolution classification was used because Landsat 8 has both 30 $\mathrm{m}$ and $15 \mathrm{~m}$ spatial resolutions for optical and panchromatic bands, respectively. To perform the object-oriented multi-resolution classification, we utilized seven bands (red, green, blue, near infrared, two shortwave infrared, panchromatic) of the data. Panchromatic band was assigned with a larger weight than the other bands to take advantage of its higher resolution $(15 \mathrm{~m})$. To obtain the best classification results, we set the object size to 80 pixels. To calibrate the classification parameters, a sample of classification results was compared to the USGS land cover data. (Figure 7a shows the selected training object). By adjusting the coefficients of the shape and compactness of the image objects to 0.2 and 0.5, a new LULC map was produced (Figure $7 \mathrm{~b}$ ). For validation of the Landsat 8 object-oriented classifycation results, we chose several targets, such as impervious surface and water bodies. Ground-truth validation results ascertain that highways and water bodies are well delineated in our classification. When the LULC map from Landsat 8 object-oriented classification was compared with the 2006 NLCD map used in the previous research (Figure 7c), the new classification results not only have more updated information and a finer spatial resolution $(15 \mathrm{~m})$, but also a better image of the objects. Highways are depicted in a more continuous shape, and all image objects are more clearly discernable. As such, the object-oriented classification was deemed to have successfully classified each LULC class, and the map was considered suitable for use in further analyses.

\subsubsection{Meteorological and Other Environmental Data}

BMP modeling requires an array of geospatial environmental data. Here, the 2007 to 2009 daily maximum and minimum air temperature time series data for Cheviot, Ohio, at $39.15^{\circ} \mathrm{N}$ and $84.62^{\circ} \mathrm{W}$ (GHCND: USC00331515) were acquired from the National Climatic Data Center (NCDC). The hourly precipitation records were obtained from the Cincinnati Northern Kentucky Airport NCDC station at $84.67^{\circ} \mathrm{W}$ and $39.04^{\circ} \mathrm{N}$ (COOP: 151855). These data were used for model development and validation.

As watershed planning is usually for a period of 15 to 20 years, and a BMP generally has a design life of 15 years, the cost-effectiveness of the BMP ensemble in the year 2030 was also examined. The 2020 to 2039 precipitation and temperature data derived from the Community Climate System Model (CCSM 3.0) (Collins et al., 2006) under the distributed World Climate Change Projections-SRES B1 scenario, as described and reported in the Fourth Assessment Report (AR4) (IPCC, 2008), 


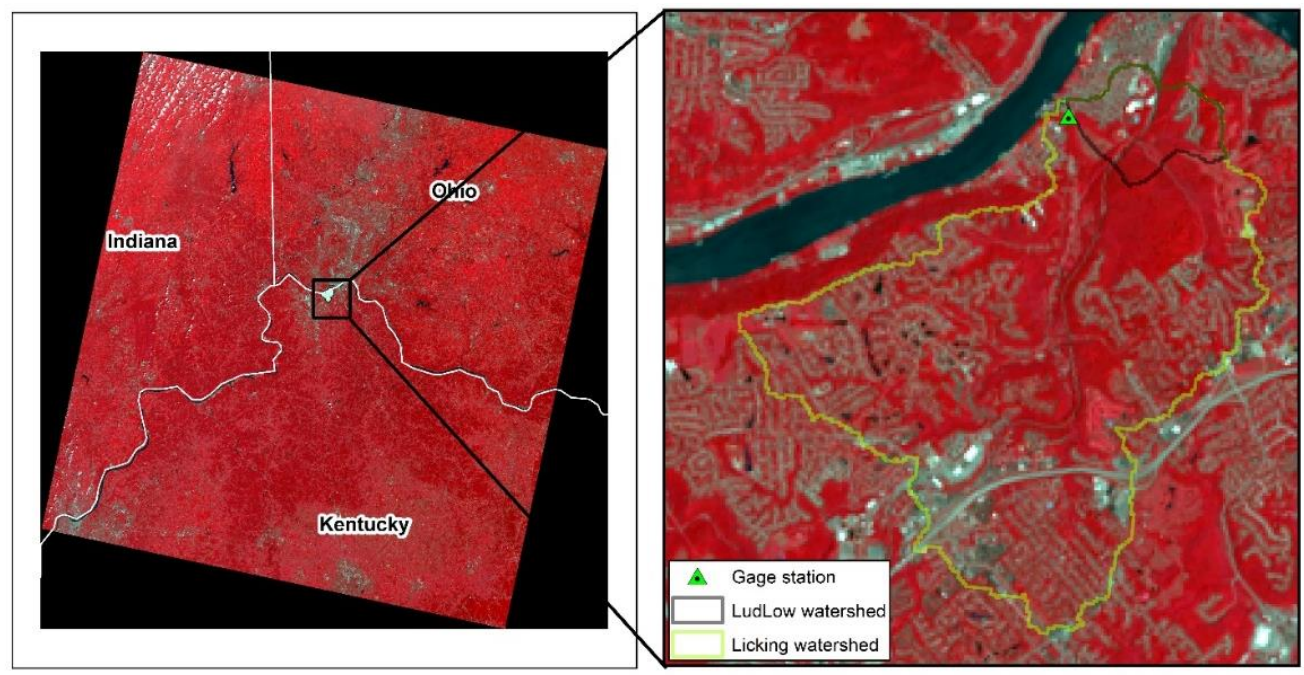

Figure 5. Landsat 8 multi-spectral image near infrared (NIR) false color combination on July 12, 2016.
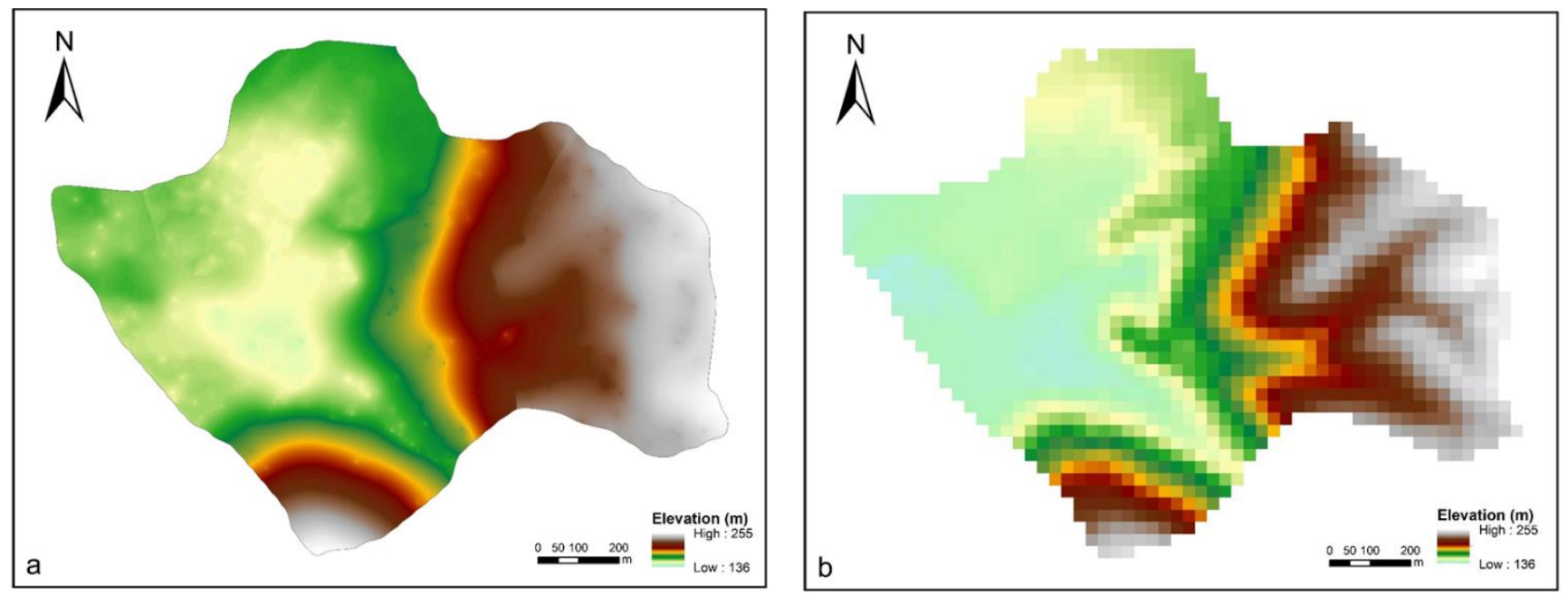

Figure 6. a) DEM collected by UAV for the Ludlow watershed at a $0.8 \mathrm{~m}$ spatial resolution; b) USGS national elevation DEM dataset at a $30 \mathrm{~m}$ spatial resolution.

was adopted to represent the future climatic conditions and used to calculate the hydrologic conditions.

Moreover, watershed boundary and stream network data were obtained from the National Hydrography Dataset Plus (NHDPlus) (USEPA, 2012). Soil data were retrieved from the State Soil Geographic (STATSGO) database published by the U.S. Department of Agriculture (USDA) (Smith et al., 1997). Daily flow data (in $\mathrm{m}^{3} / \mathrm{s}$ ) from September 1, 2007 to November 30,2009 were obtained from the USGS gage station 03260015 at $39.09^{\circ} \mathrm{N}$ and $84.56^{\circ} \mathrm{W}$ NAD27 in Pleasant Run Creek at Oak Street near Ludlow, Kentucky (USGS, 2017b); they were used for model calibration and validation.

\section{Methods}

\subsection{Selection of the Watershed Hydrologic and BMP Model}

There are a few software packages for watershed hydrol- ogic modeling, such as the Stormwater Management Model (SWMM) (Rossman, 2004), Hydrological Simulation Program Fortran (HSPF) (Bicknell et al., 2001), and System for Urban Stormwater Treatment and Analysis Integration (SUSTAIN) (Shoemaker et al., 2009; Lee et al., 2012). While both SWMM and HSPF can be used to model the hydrologic impacts of BMPs, they do not consider the economic aspects of BMPs. They also do not have optimization tools to facilitate the determination of the optimal arrangement of BMPs (Rossman, 2004).

SUSTAIN, on the other hand, is a comprehensive analyticcal and decision support system designed for BMP siting, simulation, and cost estimation at both the watershed scale and local scale (Shoemaker et al., 2009). By using process-based algorithms, its land simulation module, conveyance module, and BMP module can compute rainfall-runoff response and wash off over the land surface as well as simulate the functions and efficiencies of BMPs in removing surface runoff. The BMP 

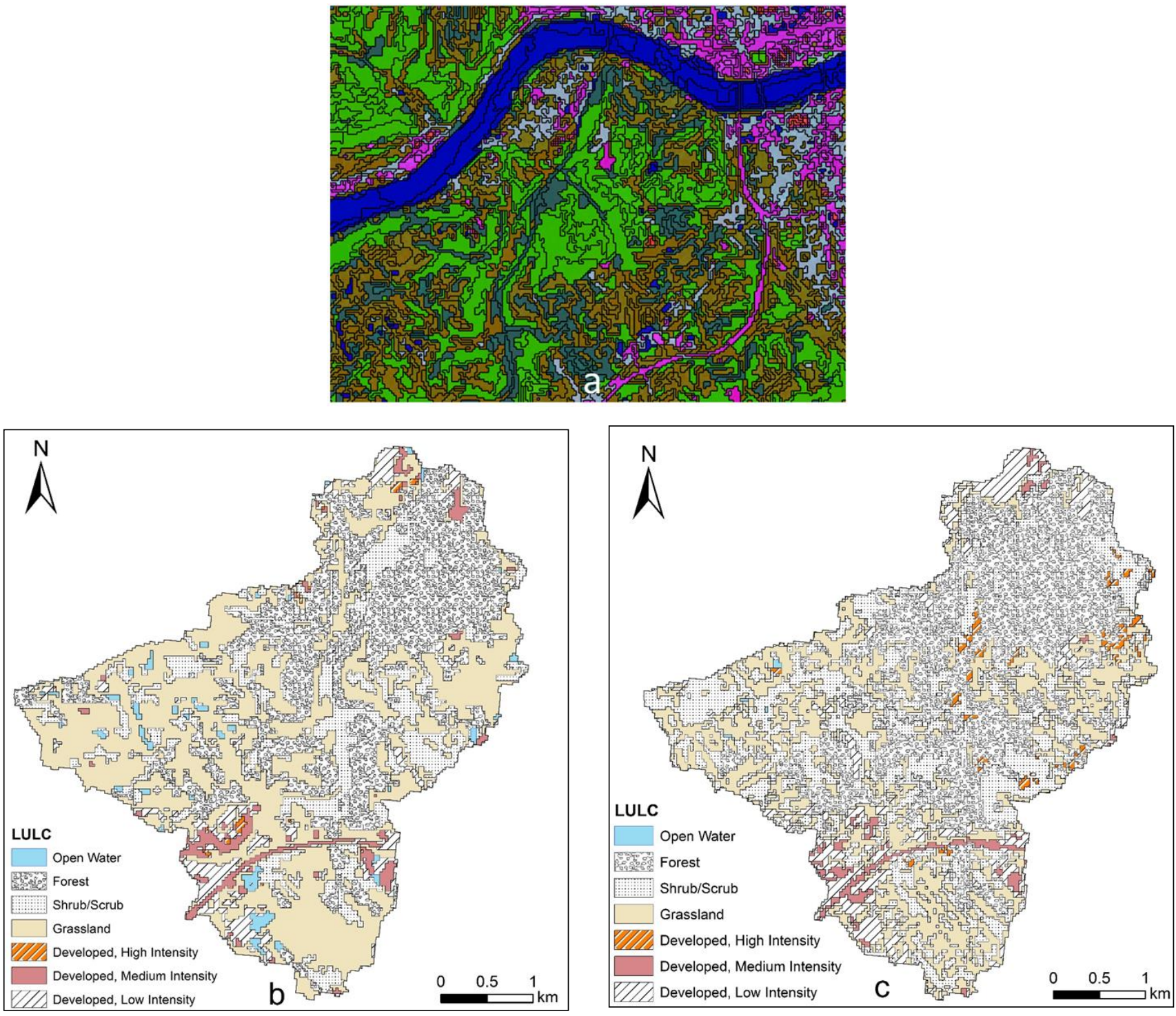

Figure 7. Object-oriented classification results for the Ludlow watershed: a) object training samples; b) Object-oriented classification results from 2016 Landsat 8 at a 15 m spatial resolution; c) 2006 NLCD map at a 30 m spatial resolution as used in Fan et al. (2017).

siting tool in SUSTAIN uses a spatial optimization process to evaluate an array of BMP arrangements and select the most appropriate BMP type, number, and location.

Developed by the U.S. Environmental Protection Agency (USEPA), SUSTAIN has been tested by the agency through various pilot studies conducted in Kansas City, Missouri (Lee et al., 2012), Louisville, Kentucky (Shoemaker et al., 2012), and Las Vegas Valley, Nevada (Sun et al., 2016). From the results of these studies, it is evident that SUSTAIN is capable of objectively and comprehensively determining the optimal arrangements of BMPs and modeling the hydrologic conditions before and after the installation of BMPs. Because of its proven capabilities, SUSTAIN was selected in the previous study and this study to determine the most appropriate number, types, arrangements and locations of BMP as well as to evaluate their costeffectiveness under the current and future climatic conditions.

\subsection{Ludlow Watershed SUSTAIN Model Development}

The same 2008 water year (from October 2007 to September 2008), as was used in the previous study, was chosen to depict the current climatic conditions and develop the base SUSTAIN model for the Ludlow watershed. It was because the weather conditions during this year were representative of the average current conditions of the watershed. Based on the meteorological data from station COOP 151855, the annual precipitation of the year of the watershed was $1,909.6 \mathrm{~mm}$, which is very close to the 30-year average precipitation value of $1,936.5$ mm (Williams Jr. et al., 2007). 
To build the base model, the $2008 \sim 2009$ weather data and the UAV DEM data were imported into SUSTAIN, and the model was run to simulate the daily flow without the BMPs. In this study, the calibration and validation of the model were performed using the Licking watershed because the only gage station in the study area is located in the Licking watershed. Besides, it encompasses the Lud- low watershed, and both watersheds have similar climate, soil, and LULC (Figure 1). To assess model performance, the simulated daily flow results were compared with the monitored flow records from the USGS gage station and the error rate was calculated according to Bicknell et al. (1996):

$$
\operatorname{Error}(\%)=\frac{\sum\left(\text { flow }_{\text {simulated }}-\text { flow }_{\text {observed }}\right)}{\sum \text { flow }_{\text {observed }}} \times 100 \%
$$

If the error rate was high, the parameter values of the model would be adjusted and the model would run again. This process was repeated iteratively by trial and error until the error rate reached the minimum value. For validation, the weather data from October 2008 to September 2009 were used to run the model with the same set of parameter values. The error rate between the flow simulation results and the gage station records of the 2009 water year was calculated. If the validation results were acceptable, the same parameter values of the Licking watershed model would be used in the Ludlow watershed model.

\subsection{BMP Siting and Cost-Effectiveness Determination}

Prior to BMP siting and modeling, we conducted some preparatory work. First, in order to perform a more detailed and thorough BMP analysis, we took advantage of the better quality DEM data acquired from the UAV imagery (Figure 6a) together with the LULC data from the Landsat 8 satellite imageries to conduct a more accurate watershed delineation. By computing the flow directions and flow accumulation threshold, seven subwatersheds were successfully delineated. Second, we imported the data pertaining to soil type, LULC, topography, stream network, the availability of flat areas, and the size of the target area to SUSTAIN. Third, similar to the previous study, we chose the Holtan-Lopez algorithm to calculate stormwater hydrology because the other method, the Green-Ampt method, does not consider the effects of vegetation root zone on infiltration rate. Fourth, to evaluate the overall runoff in the watershed, we defined the outlet for the entire Ludlow watershed as the assessment point, which is located at exactly the same place as in the previous study (Figure 8a).

For every BMP installation, one needs to consider the amount of flow reduction and the costs of installation and maintenance (Damodaram et al., 2010). Different BMPs may have different flow attenuation capabilities and costs. While a larger number of BMPs can certainly reduce more surface runoff, the costs of installing and maintaining them will increase. In this research, the cost-optimization tool in SUSTAIN was used to determine the optimal types, number, and arrangements of BMPs and to evaluate the cost-effectiveness of different BMP ensembles. Here, cost was calculated as:

$$
\operatorname{Cost}=\operatorname{Min}\left\{\sum_{j=1}^{m} \sum_{i=1}^{n}\left[\begin{array}{l}
\operatorname{Cost}_{i}\left(\operatorname{Comp}_{\text {bio }}\right) \\
+\operatorname{Cost}_{j}\left(\operatorname{Comp}_{\text {infiltrench }}\right)
\end{array}\right]\right\}
$$

where $m$ and $n$ are the respective numbers of infiltration trenches and bioretention basins installed, $i$ is the individual bioretention basin identification number, and $j$ is the infiltration trench identification number. Comp bio is the functional components of bioretention and Compinfiltreanch is the functional components of infiltration trench. Flow reduction was calculated as:

Flow reduction $_{t}(\%)=\frac{\left(\text { volume }_{t}-\text { volume }_{B M P}\right)}{\text { volume }_{t}}$

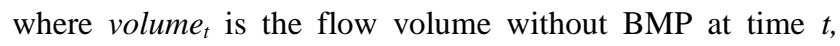
volume $_{B M P}$ is the simulated flow volume with the BMP installed at time $t$.

The data used in calculating the costs of installing and maintaining the BMPs were abstracted from the SUSTAIN cost database (USEPA, 2017). Cost-effectiveness curves were generated by calculating the percentage of flow reduction against the cost of BMP. We used the Ordinary Least Squared (OLS) fitting model to fit a logarithmic function against the costeffectiveness curve. The solution with the highest positive residual was selected as the optimal solution because the higher the residual, the more efficient the solution will be in balanceing the cost and the amount of flow reduction.

\subsection{Examining the Benefits of Fine Resolution Data in BMP Analyses}

To address our main research question whether the better quality source data could provide results that would be more indicative of the actual cost-effectiveness of the BMPs in the watershed, we sought to compare the levels of annual flow reduction and the costs of installation and maintenance of the new BMP ensembles with the results derived from coarse resolution data as reported in the previous study under the current (2008) climatic conditions.

In the first analysis, we utilized the same number of subwatersheds (three subwatersheds) and the same types of BMPs (one bioretention and two infiltration trenches) as in the previous study to safeguard that the set up and costs of BMPs of these two studies will be the same and the comparison will be appropriate. However, in this instant study, the use of a different data source may result in a different watershed delineation and BMP siting. The sizes and shapes of the three subwatersheds and the potential BMP sites can be different as well. To determine which BMP locations should be eliminated from the analyses and to find the best three-BMP-ensemble option, we used the results from preliminary model runs. After the types, arrangements, and locations of the three BMPs were determined, the cost-effectiveness of the three-BMP-ensemble was evalu- ated and compared with that of the BMP arrangement used in the early study.

The second phase of this analysis was to explore the costs and benefits if the maximum number of BMPs was installed. 
With the finer resolution UAV DEM, we managed to delineate seven (the maximum number) subwatersheds, each with many potential BMP sites. To find the best location for the BMP in each of these watersheds and to establish the best seven-BMPensemble, we again used simulation results from prelimnary studies. Then, its cost-effectiveness under the 2018 climatic conditions was calculated and compared to Fan et al. (2017).

\subsection{Examining the Future Utilities of the BMP Ensembles}

To ensure that the capital investment on BMPs will yield not only short-term but also long-term benefits, lasting throughout the whole design life span, the Ludlow watershed model was run under the 2030 climatic conditions. The 2030 percentages of flow reduction by the chosen three-BMP-ensemble and seven-BMP-ensemble and their costs were calculated and their cost-effectiveness curves and logarithmic functions were generated by the OLS logarithmic fitting model. The cost-effectiveness of these ensembles was compared. These results were also com- pared with the results from the 2008 analyses.

\section{Results}

\subsection{SUSTAIN Model Calibration and Validation}

After adjusting the parameter values of zero impervious percentage, maximum/minimum infiltration rate, depth of depression storage, maximum infiltration volume and dry time, the Licking watershed SUSTAIN model reached a percentage error rate of $1.98 \%$ for the entire 2008 water year. The Pearson correlation coefficient between the simulated daily flow and the monitored values is 0.76 (Table 3 ). Seasonally, the error percentage is $7.14 \%$ for winter and $9.43 \%$ for summer. The validation using 2009 weather data yielded even more promising results with error rates of less than $5.50 \%$ and correlation coefficients equal to or above 0.85 (Table 3 ). Based on the recommenddation of Bicknell et al. (1996), the model was regarded as accurate enough to simulate the hydrology of the area. Its parameter values were used in the Ludlow watershed SUSTAIN model for further analyses.

\subsection{Improvements of BMP Analyses by Using High Resolution Data}

In the previous study, with the $30 \mathrm{~m}$ DEM and LULC data from USGS, three subwatersheds were delineated and three BMPs were sited. A bioretention basin was sited in subwatershed 2 and infiltration trenches were sited in subwatershed 1 and subwatershed 3 (Figure 8a). In this study, even for the threeBMP-ensemble siting, the better quality data provided a slightly different subwatershed delineation. The new subwatersheds had different sizes and shapes, and interestingly, smoother boundaries (Figure 8b). There were also more candidate sites for BMP installation. After a series of elimination, the best threeBMP-ensemble was determined (Figure $8 \mathrm{~b}$ and Table 2).

The finer resolution data also enabled us to have a more real- istic watershed delineation. We managed to partition the Ludlow watershed into more subwatersheds, seven in all (Fig- ure 9), each with more potential BMP sites. Figures $10 \mathrm{~b}$ and $10 \mathrm{~d}$ show that there were seventeen bioretention and eight infiltration trench potential sites. When Figure 10a is compared with $10 \mathrm{~b}$ and Figure $10 \mathrm{c}$ with $10 \mathrm{~d}$, the improvement afforded by fine resolution data in identifying potential BMP sites is unequivocal. With more options, we could make a more informed decision as we were considering the best possible type, arrangement, and location of BMP in each subwatershed. This again is a great improve- ment over the earlier study. The seven-BMPensemble that we finally selected entailed installing bioretentions in subwatersheds $1,3,4,6,7$ and infiltration trenches in subwatersheds 2 and 5 (Figure 9 and Table 2).

Also with UAV DEM at a $0.8 \mathrm{~m}$ spatial resolution and LULC data derived from multi-spectral satellite imagery at a $15 \mathrm{~m}$ spatial resolution, better shapes and sizes of the BMPs were depicted. In the earlier study, the shapes of the BMPs identified by the BMP siting tool were like triangles. This may be because the coarse resolution data were too crude to depict the fine details of the DEM and LULC, and the shape of the BMP site was formed simply by connecting the centroids of a few pixels. In this study, with the finer resolution data, more detailed information was provided, which facilitated the portrayal of a more accurate picture of the environmental conditions and the estimation of the actual shapes and sizes of BMPs.

\subsection{BMP Analyses under Current 2008 Climatic Conditions}

Figure 11 shows the cost-effectiveness of the three BMPs under the 2008 climatic conditions for both the previous and the current studies. In each graph, the small circles represent the entire solution population. The triangles depict the least cost solutions, and the fitted line represents the cost-effectiveness curve. At the point when the curve starts to level off (as depicted by the diamond), it reaches the optimal cost-effectiveness solution with the least expense but the maximum flow attenuation.

The cost-effectiveness curves of both the earlier and the current studies have a non-linear relationship between costs and flow reduction; as the percentage of flow reduction increases, the cost will increase. Nonetheless, the curve for the threeBMP-ensemble used in this study (Figure 11b) is notably steeper than the one for the three BMPs used in the previous study (Figure 11a). The OLS logarithmic function for the cost-effectiveness curve for the previous study is:

$y=23.004 \operatorname{Ln}(x)+30.953$

whereas the fitted function for the instant study is:

$y=37.369 \operatorname{Ln}(x)+18.836$

The coefficient of cost increase for the previous study is 23.004, and for this study, it is 37.369. These results therefore demonstrate that the instant three-BMP-ensemble will be more cost-effective than the BMP arrangement identified earlier. In the current study, as the amount of flow reduction continues to 

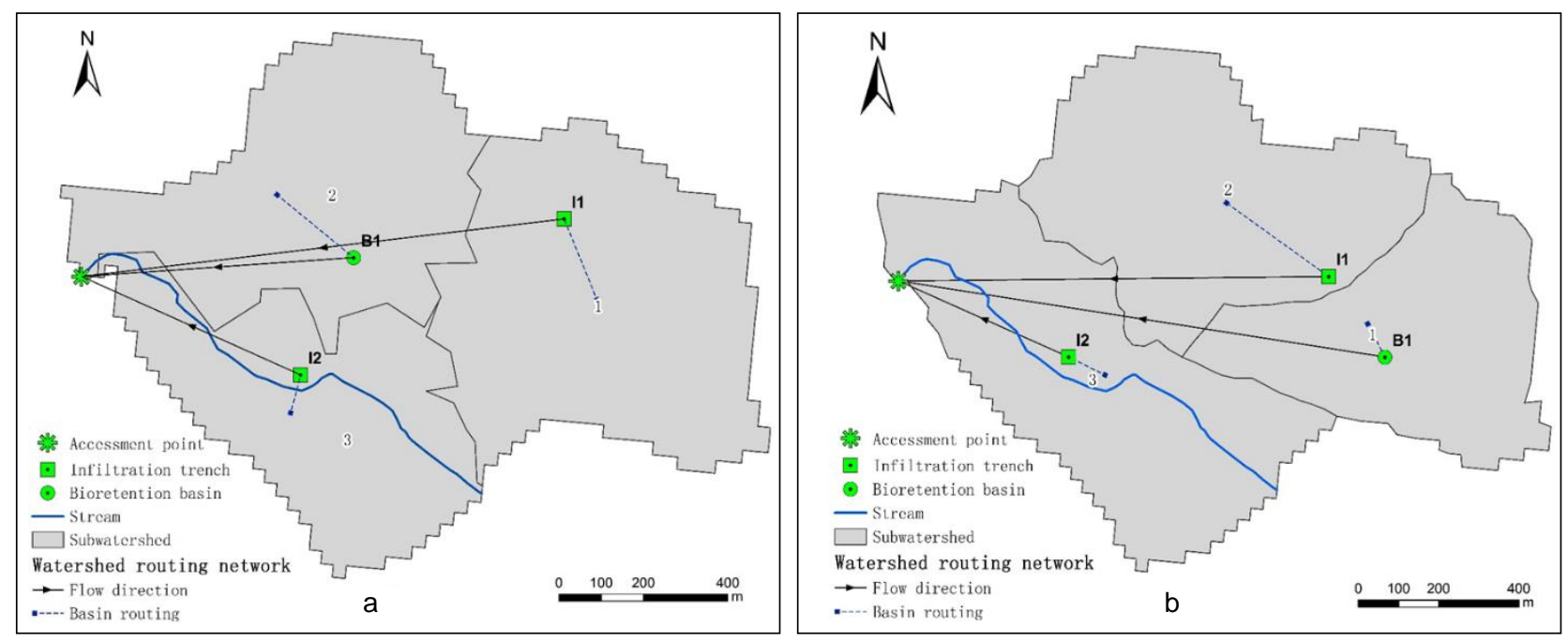

Figure 8. a) BMP arrangement used in Fan et al. (2017); b) the arrangement of the three-BMP-ensemble adopted in this study based on finer resolution DEM and LULC data.

Table 2. Description of the Selected Three-BMP-Ensemble and Seven-BMP-Ensemble Used in this Study

\begin{tabular}{llllll}
\hline & Subwatershed & BMP & Type & Length $(\mathrm{m})^{*}$ & Width (m) \\
\hline \multirow{2}{*}{ Three-BMP- } & 1 & B1 & bioretention & 523 & 34.0 \\
Ensemble & 2 & I1 & infiltration trench & 413 & 37.0 \\
& 3 & I2 & infiltration trench & 274 & 31.0 \\
\hline & 1 & B1 & bioretention & 110 & 30.4 \\
Seven-BMP- & 2 & I1 & infiltration trench & 200 & 38.0 \\
Ensemble & 3 & B3 & bioretention & 583 & 35.0 \\
& 5 & B4 & bioretention & 178 & 34.0 \\
& 6 & I2 & infiltration trench & 413 & 39.0 \\
\end{tabular}

*Length is defined as a decision parameter for BMPs

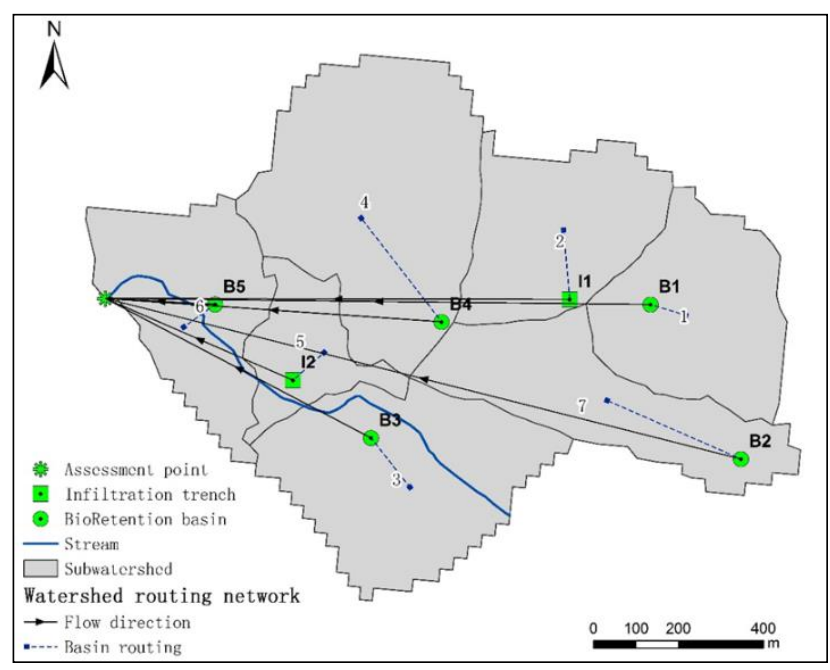

Figure 9. BMP types and locations of the selected seven-BMPensemble used in the analysis.

increase, a lesser amount of cost increase will be incurred. Ac- tually, in the study of Fan et al. (2017), the optimal solution (the diamond in Figure 11a) can reduce $63.97 \%$ of the flow volume at the cost of 4.5 million USD. Nevertheless, in this study, the optimization results indicate that the optimal solution for the three-BMP-ensemble can reduce $65.66 \%$ of flow at a cost of only 3.6 million USD (Figure 11b).

Figure 12 shows the 2008 cost-effectiveness curve for the chosen seven-BMP-ensemble. The logarithmic fitted function for the cost-effectiveness curve is:

$$
y=30.693 \operatorname{Ln}(x)+17.93
$$

When the results of this study were contrasted with the results from Fan et al. (2017), the advantages of using better quality data are obvious. Here, if all seven identified BMPs were installed in the seven subwatersheds, the optimal solution (the diamond in Figure 12) under the 2008 climatic condition would cost 5.6 million USD and would reduce $73.51 \%$ of annual flow. Hence, the maximum practicable amount of flow reduction would increase by $9.54 \%$ at an additional cost of 1.1 million USD than what Fan et al. (2017) had reported. 
Table 3. Calibration and Validation Results for the Licking Watershed SUSTAIN Model

\begin{tabular}{|c|c|c|c|c|c|c|}
\hline & Time & & $\begin{array}{l}\text { Observed } \\
\text { daily flow }\left(\mathrm{m}^{3} / \mathrm{s}\right)\end{array}$ & $\begin{array}{l}\text { Simulated } \\
\text { daily flow }\left(\mathrm{m}^{3} / \mathrm{s}\right)\end{array}$ & $\begin{array}{l}\text { Error } \\
\text { rate* }^{*}\end{array}$ & $\begin{array}{l}\text { Correlation } \\
\text { coefficient }\end{array}$ \\
\hline \multirow[t]{3}{*}{ Calibration } & 2008 water year & Oct $07 \sim$ Sep 08 & 0.2627 & 0.2679 & $1.98 \%$ & 0.76 \\
\hline & 2008 Winter & Dec $07 \sim$ Feb 08 & 0.8679 & 0.9299 & $7.14 \%$ & 0.92 \\
\hline & 2008 Summer & Jun $08 \sim$ Aug 08 & 0.3795 & 0.4153 & $9.43 \%$ & 0.99 \\
\hline \multirow[t]{3}{*}{ Validation } & 2009 water year & Oct $08 \sim$ Sep 09 & 0.2454 & 0.2541 & $3.55 \%$ & 0.85 \\
\hline & 2009 Winter & Dec $08 \sim$ Feb 09 & 0.8134 & 0.8581 & $5.49 \%$ & 0.93 \\
\hline & 2009 Summer & Jun $09 \sim$ Aug 09 & 0.3419 & 0.3584 & $4.83 \%$ & 0.99 \\
\hline
\end{tabular}

*The percentage error is used as error rate

\subsection{BMP Simulations under Future 2030 Climatic Conditions}

Figure 13 shows the 2030 hydrologic conditions after the installation of the three-BMP-ensemble and the seven-BMPensemble. It reveals that the optimal cost-effectiveness BMP solution for the three-BMP-ensemble will cost 4.0 million USD and will reduce $63.02 \%$ of the flow, whereas the seven-BMPensemble will cost 5.9 million USD with a reduction of $72.85 \%$ in annual flow. Thus, both the three-BMP-ensemble and the seven-BMP-ensemble will still be adequate to reduce surface runoff even under the future 2030 climatic conditions. When compared with the 2008 current climatic conditions (Figures $11 \mathrm{~b}$ and 12), the amount of flow attenuated by the three-BMPensemble in 2030 will be less $(2.64 \%$ less), but the cost will be higher (0.4 million USD more) (Figures $11 \mathrm{~b}$ and $13 \mathrm{a})$. Similarly, the seven-BMP-ensemble will reduce $0.66 \%$ less flow but at an additional cost of 0.3 million USD (Figures 12 and 13b). The slightly higher cost in 2030 is attributable to the main- tenance cost from 2008 to 2030.

Regarding the 2030 logarithmic fitted functions for the costeffectiveness curves, the equation for the three-BMP-ensemble is:

$y=27.659 \operatorname{Ln}(x)+27.872$

The equation for the seven-BMP-ensemble is:

$y=21.865 \operatorname{Ln}(x)+33.178$

They show that the coefficients of cost increase for the three-BMP-ensemble under the 2030 climate regime is 27.659 and that for the seven-BMP-ensemble is 21.865 .

\section{Discussion}

The results of the analyses are informative; they can be used further to determine the most important BMP in reducing surface flow. Under the current climatic conditions, out of the seven BMPs in the ensemble, the two infiltration trenches are responsible in reducing $36 \%$ of the total flow, while the five bioretentions can reduce $64 \%$ of the total flow (Table 4). Among them, the infiltration trench 12 will provide the largest flow reduction, followed by B3 and B2 bioretentions. When the location maps of the seven-BMP-ensemble (Figure 9) and the threeBMP-ensemble (Figure 8b) were compared, they show that I2 and $\mathrm{I} 1$ are the only BMPs that share similar locations in the two ensembles. Thus, regardless of the number, shape, and size of the subwatersheds, the BMP siting tool in SUSTAIN consistently identified these two BMPs in these locations, suggesting that $\mathrm{I} 2$ is the most important BMP and should be given priority consideration in stormwater management.

The results can also help in identifying the most costeffective BMP ensemble. Under the current climatic conditions, the optimal BMP solutions from the cost-effectiveness curves for the three-BMP-ensemble analysis show that the two infiltration trenches and one bioretention BMP can reduce $65.66 \%$ of flow at a cost of 3.6 million USD, whereas for the sevenBMP-ensemble with two infiltration trenches and five bioretention BMPs, the percentage of flow reduction will be $73.51 \%$, and the cost will be 5.6 million USD. Hence, the four additional bioretentions in the seven-BMP-ensemble can reduce a further $7.85 \%$ of flow at an additional cost of 2 million USD. An examination of the logarithmic fitted functions of the cost-effectiveness curves for the two BMP-ensembles (Equations 5 and 6) also reveals that the coefficient for cost increase is 30.693 for the seven-BMP-ensemble but 37.369 for the three-BMPensemble, indicating that the percentage of flow reduction per unit cost increase is higher for the three-BMP-ensemble.

Similarly, under the 2030 climate regimes, the coefficient of cost increase of the three-BMP-ensemble is higher than the seven-BMP-ensemble (27.659 and 21.865, respectively). Thus, even under the future climatic conditions, the cost will actually be lower for the three-BMP-ensemble than for the sevenBMP-ensemble to reduce the same amount of flow. In essence, if the water management goal is to achieve the best flow reduction with the least cost, the three-BMP-ensemble will be more cost-effective, and it should be installed.

Nonetheless, the seven-BMP-ensemble can also be a suitable solution for the study area. Under the current climatic conditions, the optimal cost-effective solution for the seven-BMPensemble shows that it can reduce $73.51 \%$ of flow, while the three-BMP-ensemble can only achieve a $65.66 \%$ flow reduction. Moreover, if the maximum amounts of flow reduction (instead of the optimal cost-effective solutions) are considered, the three-BMP-ensemble can reduce a maximum $65.84 \%$ of sur face flow, while the seven-BMP-ensemble can reduce a maximum $76.24 \%$ of flow (Figures $11 \mathrm{~b}$ and 12). This additional $10.40 \%$ of maximum flow reduction capacity afforded by the seven-BMP-ensemble can play an important role in flood mitigation during heavy storms. Hence, if the objective is to max- 

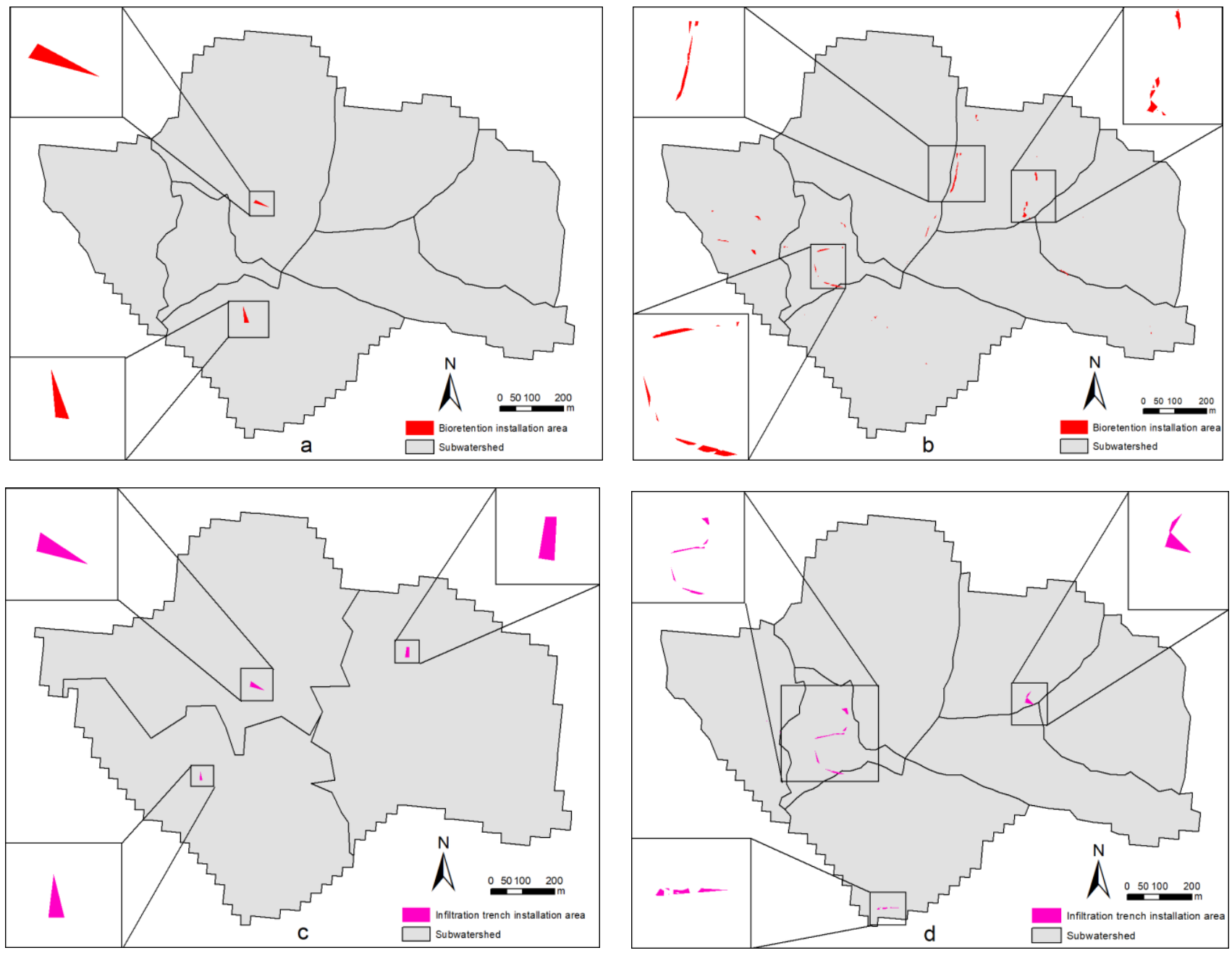

Figure 10. The BMP siting results derived from the original DEM at a $30 \mathrm{~m}$ resolution as reported in Fan et al. (2017) and the new UAV DEM at a $0.8 \mathrm{~m}$ resolution: a) previous siting results for bioretention; b) new siting results for bioretention; c) previous siting results for infiltration trench; d) new siting results for infiltration trench.
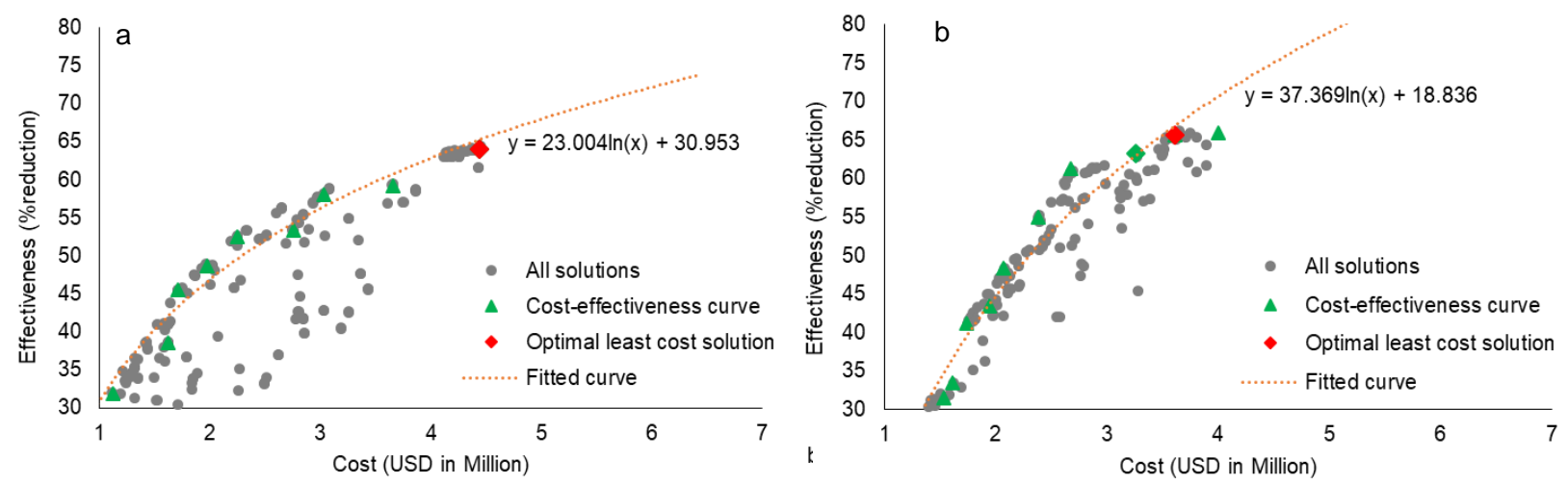

Figure 11. Results of the 2008 cost-effectiveness analyses for a) the earlier study as reported in Fan et al. (2017); and b) the threeBMP-ensemble in this study.

imize the amount of flow reduction and to mitigate urban floods notwithstanding the cost, the water manager should choose the seven-BMP-ensemble.
Of note is that the results of this study show that the percentages of flow reduction by the BMP ensembles in 2030 will be slightly less than those in 2008 (2.64\% less for the three- 
BMP-ensemble and $0.66 \%$ less for the seven-BMP-ensemble). However, this finding has to be used with reservetion. First, model simulation results are dependent on input data. The IPCC AR4 B1 future climate scenario portrays that the weather in 2030 would be drier than the 2008 base year in the study area (Table 5). With less precipitation, the utility of the BMPs in flood mitigation can be decreased. Nevertheless, this study shows that the seven-BMP-ensemble could still reduce $72.85 \%$ of surface runoff in 2030, which will contribute substantially to flood mitigation.

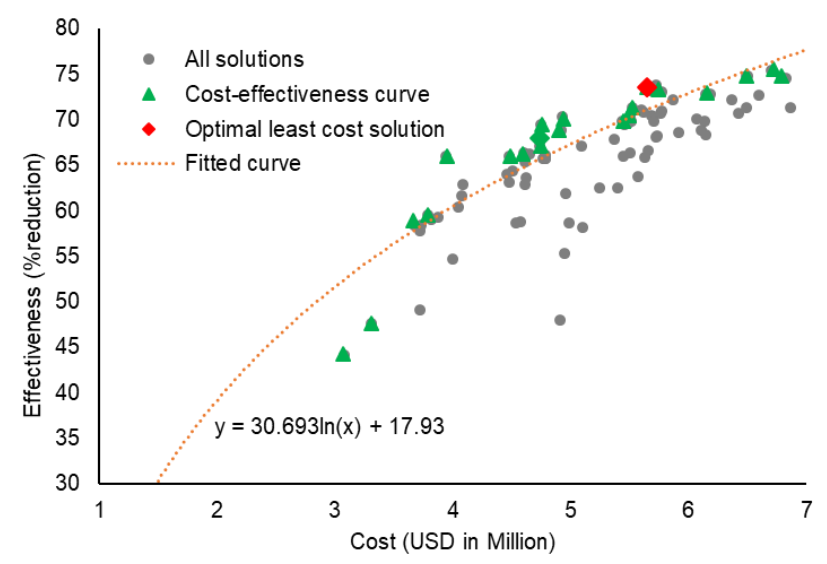

Figure 12. Results of the cost-effectiveness analysis for the seven-BMP-ensemble under 2008 climatic conditions.

Second, the B1 climate scenario adopted in this study is a hypothetical portrayal. While the assumptions underlying this scenario are reasonable, things may change, and the amount of carbon dioxide emission may be different. The future climate in the Ohio Valley could be wetter, and the amount of flow reduction could be increased. Besides, with global climate change, there may be more extreme events, such as torrential thunderstorms (Field, 2012), which have yet to be accounted for in the projected climatic data. Furthermore, the climate projecttions may not be accurate. IPCC is updating its projections for the

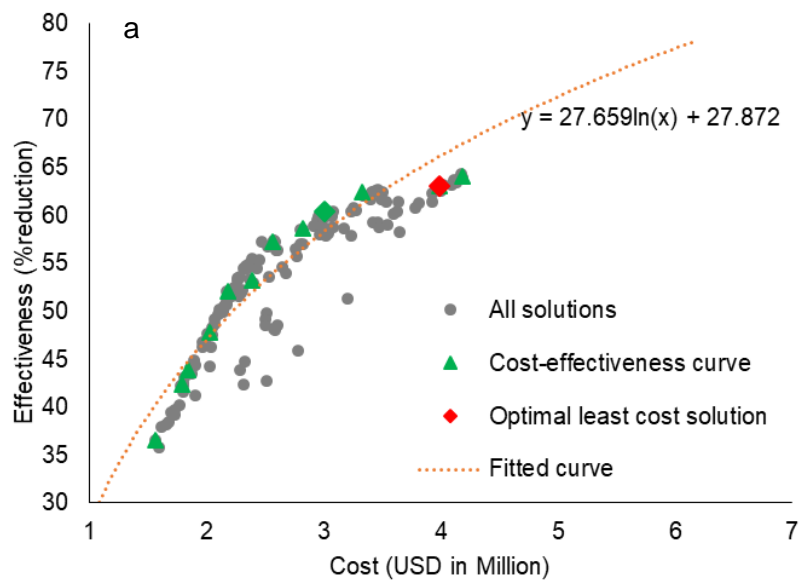

future climate regimes regularly, and there are other advances in climate modeling, which might provide a different set of climate regimes, contrary to what we were using in this study. Regardless of the future climate regimes, the results from this study confirm that installation of BMPs can help ameliorate flash floods in the Ludlow watershed.

\section{Conclusions}

The results of the analyses clearly show that BMPs are effective in reducing surface runoff even in a watershed with mixed land use under both the current and the future climatic conditions. Also, by comparing the results of this work with the earlier work, this study clearly demonstrates the advantages of using better quality data in BMP studies. Because BMPs are designed to operate in a small area under a local site scale, the use of finer resolution data is more suitable. First, better quality data can help to enhance subwatershed delineation. In this research, seven subwatersheds were delineated, instead of three subwatersheds as in the study by Fan et al. (2017) using coarse resolution data. Second, data with finer resolution can enhance BMP siting. By providing more potential BMP implementation solutions, the most optimal BMP configuration in stormwater runoff management can be determined. In this study, five bioretention basins and two infiltration trenches can be sited, which is a great improvement over the earlier study where only two infiltration trenches and one bioretention BMP can be installed. Third, a more accurate estimate of the BMP cost-effectiveness can be derived. By using UAV high resolution data, it reveals that more BMPs can be installed and together they are capable to attenuate more flow (73.51\% instead of $63.97 \%$ ) under the current climate conditions. Also the three-BMP-ensemble will actually cost less than what the previous study suggested.

Based on the results, the three-BMP-ensemble and, specifically, the I 2 infiltration trench, was found to be the most effecttive flood mitigation tool. Additionally, the results show that the identified BMP ensembles will still be instrumental in reducing surface flow in the future in the face of impending climate

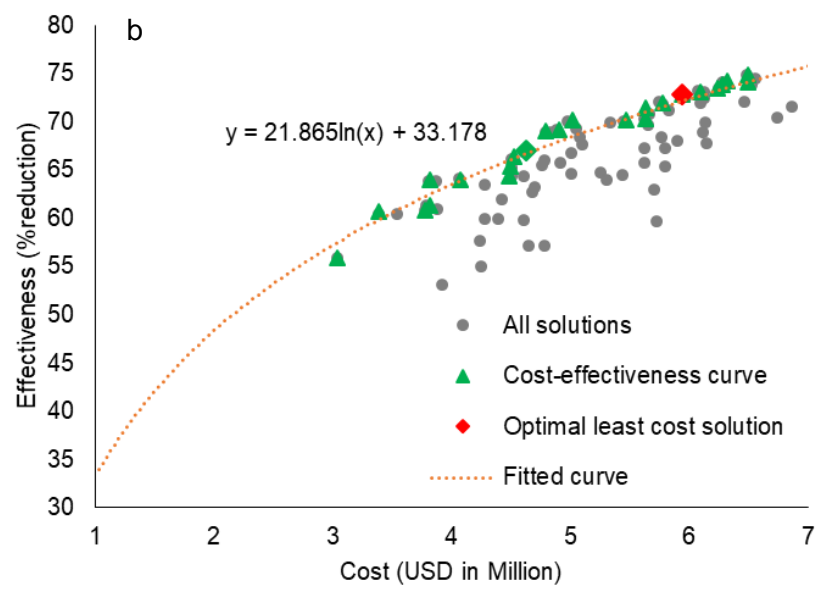

Figure 13. 2030 cost-effectiveness curve for a) the three-BMP-ensemble; b) the seven-BMP-ensemble arrangements as used in this study. 
Table 4. Percentage Flow Reduction for Each BMP in the Seven-BMP-Ensemble under the 2008 Climatic Conditions

\begin{tabular}{llllllll}
\hline Subwatershed & 1 & 2 & 3 & 4 & 5 & 6 & 7 \\
\hline BMP & B1 & I1 & B3 & B4 & I2 & B5 & B2 \\
Flow reduction (\%) & 9.313 & 14.059 & 15.811 & 10.010 & 21.941 & 13.665 & 15.115 \\
\hline
\end{tabular}

Table 5. Temperature and Precipitation Regimes in 2030 as Compared with Current 2008 Climatic Condition*

\begin{tabular}{|c|c|c|c|c|c|c|c|c|c|}
\hline & & Winter & & Spring & & Summer & & Fall & \\
\hline \multirow{3}{*}{ Temperature $\left({ }^{\circ} \mathrm{C}\right)$} & Year & Average & Diff & Average & Diff & Average & Diff & Average & Diff \\
\hline & 2008 & -0.14 & & 10.47 & & 23.30 & & 13.15 & \\
\hline & 2030 & 1.20 & +1.34 & 12.90 & +2.43 & 24.40 & +1.10 & 14.40 & +1.25 \\
\hline \multirow[t]{2}{*}{ Precipitation (mm) } & 2008 & 110.24 & & 157.40 & & 85.85 & & 43.01 & \\
\hline & 2030 & 66.28 & -43.96 & 97.24 & -60.16 & 82.30 & -3.55 & 67.60 & +24.59 \\
\hline
\end{tabular}

*Information is abstracted from IPCC (2007) and NOAA (2012)

change. Unequivocally, this new information will be valuable to water managers as they formulate strategies for stormwater management and flood mitigation.

This study is a step forward to a more accurate and informative BMP analysis. It is the first attempt using both UAV and satellite remote sensing in such analyses. It is cheap, convenient, and efficient, and it can produce reliable results. With little modification, the method can be used by other researchers in other study areas; particularly in areas without quality data.

While the findings of this research can be useful to scientific literature, the work presented here could be improved. First, the stock camera in the UAV could be modified to capture images with different bands to produce multi-spectral imagery. As such, high resolution LULC maps could be generated without relying on satellite remote sensing. This could further improve the resolution and the accuracy of the model and reduce the work involved in image processing. Second, the future temperature data retrieved from IPCC AR4 B1 scenario are linearly extrapolated. Besides, AR4 does not provide any future climate scenarios with extreme weather conditions. Future research can explore the performances of BMPs under these events.

\section{References}

Benz, U.C., Hofmann, P., Willhauck, G., Lingenfelder, I., and Heynen, M. (2004). Multi-resolution, object-oriented fuzzy analysis of remote sensing data for GIS-ready information. ISPRS J. Photogramm. Remote Sens. 58, 239-258. https://doi.org/10.1016/j.isprsjprs. 2003.10.002

Berni, J., Zarco-Tejada, P., Suárez, L., González-Dugo, V., and Fereres, E. (2009). Remote sensing of vegetation from UAV platforms using lightweight multispectral and thermal imaging sensors. Int. Arch. Photogramm. Remote Sens. Spatial Inform. Sci., 6. 38.

Bicknell, B.R., Imhoff, J.C., Kittle Jr, J.L., Donigian Jr, A.S., and Johanson, R.C. (1996). Hydrological Simulation Program-FORTRAN. User's Manual for Release 11. US Environmental Protection Agency, Washington DC.

Bicknell, B.R., Imhoff, J.C., Kittle Jr, J.L., Jobes, T.H., Donigian Jr, A.S., and Johanson, R. (2001). Hydrological Simulation ProgramFORTRAN: HSPF, Version 12 User's Manual. AQUA TERRA Consultants, Mountain View, California.

Collins, W.D., Bitz, C.M., Blackmon, M.L., Bonan, G.B., Bretherton, C.S., Carton, J.A., Chang, P., Doney, S.C., Hack, J.J., and Henderson, T.B. (2006). The community climate system model version 3 (CCSM3). J. Climate. 19, 2122-2143. https://doi.org/10.1175/
JCLI3761.1

Damodaram, C., Giacomoni, M.H., Prakash Khedun, C., Holmes, H., Ryan, A., Saour, W., and Zechman, E.M. (2010). Simulation of combined best management practices and low impact development for sustainable stormwater management. J. Am. Water Resour. Assoc. 46, 907-918. https://doi.org/10.1111/j.1752-1688.2010.00462.x

DJI. (2017). Phantom 4. https://www.dji.com/phantom-4.

ESRI. (2017). Drone2Map for ArcGis. http://www.esri.com/products/ drone2map.

Fan, R., Tong, S.T.Y., and Lee, J.G. (2017). Determining the optimal BMP arrangement under current and future climate regimes: case study. J. Water Resour. Plann. Manage. 143, 05017009. https://doi. org/10.1061/(ASCE)WR.19435452.0000816

Field, C.B. (2012). Managing the Risks of Extreme Events and Disasters to Advance Climate Change Adaptation: Special Report of the Intergovernmental Panel on Climate Change. Cambridge University Press, Cambridge.

Fry, J.A., Xian, G., Jin, S., Dewitz, J.A., Homer, C.G., Limin, Y., Barnes, C.A., Herold, N.D., and Wickham, J.D. (2011). Completion of the 2006 national land cover database for the conterminous United States. Photogrammetric Eng. Remote Sens. 77(9), 858-864.

Harvey, M.C., Pearson, S., Alexander, K.B., Rowland, J., and White, P. (2014). Unmanned aerial vehicles (UAV) for cost effective aerial orthophotos and digital surface models (DSMs), Proc. New Zealand Geothermal Workshop, 2014.

IPCC (Intergovernmental Panel on Climate Change). (2007). World climate change projections-SRES B1 scenario final data. https:// www.ipcc.ch/publications_and_data/ar4/wg1/en/spmsspmprojections-of.html.

IPCC (Intergovernmental Panel on Climate Change). (2008). Climate Change 2007: Synthesis Report. Contribution of Working Groups I, II and III to the Fourth Assessment Report of the Intergovernmental Panel on Climate Change. IPCC, Geneva, Switzerland.

Jacquin, A., Misakova, L., and Gay, M. (2008). A hybrid object-based classification approach for mapping urban sprawl in periurban environment. Landscape Urban Plan. 84, 152-165. https://doi.org/ 10.1016/j.landurbplan.2007.07.006

Kerr, J.T. and Ostrovsky, M. (2003). From space to species: ecological applications for remote sensing. Trends Ecol. Evol. 18, 299-305. https://doi.org/10.1016/S0169-5347(03)00071-5

Lee, J.G., Selvakumar, A., Alvi, K., Riverson, J., Zhen, J.X., Shoemaker, L., and Lai, F. (2012). A watershed-scale design optimization model for stormwater best management practices. Environ. Modell. Softw., 37, 6-18. https://doi.org/10.1016/j.envsoft.2012.04. 011

Li, C., Wang, J., Wang, L., Hu, L., and Gong, P. (2014). Comparison of classification algorithms and training sample sizes in urban land classification with Landsat thematic mapper imagery. Remote Sens. 6, 964-983. https://doi.org/10.3390/rs6020964 
Liu, H., Wang, L., Sherman, D., Gao, Y., and Wu, Q. (2010). An objectbased conceptual framework and computational method for representing and analyzing coastal morphological changes. Int. J. Geogr. Inf. Sci., 24, 1015-1041. https://doi.org/10.1080/13658810903270 569

Liu, Y., Engel, B.A., Flanagan, D.C., Gitau, M.W., McMillan, S.K., and Chaubey, I. (2017). A review on effectiveness of best management practices in improving hydrology and water quality: needs and opportunities. Sci. Total Environ. 601, 580-593. https://doi.org/ 10.1016/j.scitote nv.2017.05.212

Mitchell, J.J., Glenn, N.F., Anderson, M.O., Hruska, R.C., Halford, A., Baun, C., and Nydegger, N. (2012). Unmanned aerial vehicle (UAV) Hyperspectral remote sensing for dryland vegetation moni- toring, Proc. of hyperspectral Image and Signal Processing (WHIS- PERS), 4th Workshop on IEEE, 1-10. https://doi.org/10.1109/ WHI SPERS.2012.6874315

NCDC (National Climatic Data Center). (2012). Monthly precipitation data. https://www.ncdc.noaa.gov/cdo-web.

NewFlightcharters. (2017). New flight charters. http://newflightchar ters.com

Rock, G., Ries, J., and Udelhoven, T. (2011). Sensitivity analysis of UAV-photogrammetry for creating digital elevation models (DEM), Proc. of Conference on Unmanned Aerial Vehicle in Geomatics.

Rossman, L. (2004). Storm Water Management Model (SWMM Version 5.0) User's Manual. US Environmental Protection Agency, Cincinnati, Ohio.

Shoemaker, L., Riverson, J., Alvi, K., Zhen, J.X., Paul, S., and Rafi, T. (2009). SUSTAIN: a Framework for Placement of Best Management Practices in Urban Watersheds to Protect Water Quality. US Environmental Protection Agency, Washington, DC.

Shoemaker, L., Riverson, J., Alvi., K., Zhen, J.X., and Murphy, R. (2012). Report on Enhanced Framework (SUSTAIN) and Field Applications to Placement of BMPs in Urban Watersheds. US Environmental Protection Agency, Washington, D.C.

Slonecker, E.T., Jennings, D.B., and Garofalo, D. (2001). Remote sensing of impervious surfaces: a review. Remote Sens. Rev. 20, 227-255. https://doi.org/10.1080/027572501095 32436

Smith, R.A., Schwarz, G.E., and Alexander, R.B. (1997). Regional interpretation of water-quality monitoring data. Water Resour. Res. 33, 2781-2798. https://doi.org/10.1029/97WR02171

Snead, D.B., and Maidment, D.R. (2000). Development and Application of Unsteady Flood Models Using Geographical Information Systems. Center for Research in Water Resources, University of Texas at Austin, Austin, Texas.

Stroppiana, D., Migliazzi, M., Chiarabini, V., Crema, A., Musanti, M., Franchino, C., and Villa, P. (2015). Rice yield estimation using multispectral data from UAV: a preliminary experiment in northern Italy. Geoscience and Remote Sensing Symposium (IGARSS). IEEE Int. 4664-4667. https://doi.org/10.1109/IGARSS.2015.7326869

Sun, Y., Tong, S., and Yang, Y.J. (2016). Modeling the cost-effectiveness of stormwater best management practices in an urban watershed in Las Vegas Valley. Appl. Geogr. 76, 49-61. https://doi.org/10.1016/j. apgeog.2016.09.005

Themistocleous, K. (2014). The use of UAV platforms for remote sensing applications: case studies in Cyprus. Second International Conference on Remote Sensing and Geoinformation of the Environment (RSCy2014), Proc. of SPIE, 9229, 92290S-1. https://doi. org/10.1117/12.2069514

Trimble. (2017). eCognition essentials. http://www.ecognition.com/.

Tucker, C.J. (1979). Red and photographic infrared linear combinations for monitoring vegetation. Remote Sens. Environ., 8, 127-150. https://doi.org/10.1016/0034-4257(79)90013-0

U.S. Federal Insurance Administration. (1979). Flood Insurance Study, City of Ludlow, Kentucky, Kenton County. Federal Insurance Administration, Washington DC.

USEPA (U.S. Environmental Protection Agency). (2012). National Hydrography Dataset Plus NHDPlus. https://www.epa.gov/water data/nhdplus-national-hydrography-dataset-plus.

USEPA (U.S. Environmental Protection Agency). (2017). System for Urban Stormwater Treatment and Analysis IntegratioN (SUSTAIN). https://www.epa.gov/water-research/system-urban-stormwatertreatment-and-analysis-integration-sustain.

USGS (U.S. Geological Survey). (2015). National Elevataion DataSet (NED). https://lta.cr.usgs.gov/NED.

USGS (U.S. Geological Survey). (2017a). Landsat 8. https://landsat. usgs.gov/landsat- 8 .

USGS (U.S. Geological Survey). (2017b). National Water Information System: Water Interface. https://waterdata.usgs.gov/nwis/uv? site_no $=03260015$.

Uto, K., Seki, H., Saito, G., and Kosugi, Y. (2013). Characterization of rice paddies by a UAV-mounted miniature hyperspectral sensor system. IEEE J. Sel. Top. Appl. Earth Obs. Remote Sens. 6, 851860. https://doi.org/10.1109/JSTARS.2013.2250921

Uysal, M., Toprak, A., and Polat, N. (2015). DEM generation with UAV photogrammetry and accuracy analysis in Sahitler hill. Meas. 73, 539-543. https://doi.org/10.1016/j.measurement.2015.06.010

Wickham, J.D. and Flather, C.H. (2013). Integrating biodiversity and drinking water protection goals through geographic analysis. $D i$ vers. Distrib. 19, 1198-1207. https://doi.org/10.1111/ddi.12103

Williams Jr., C.N., Menne, M., Vose, R., and Easterling, D. (2007). Long-term daily and monthly climate records from stations across the contiguous United States. United States Historical Climatology Network. Carbon Dioxide Information Analysis Center, Oak Ridge National Laboratory, US Department of Energy. http://cdiac.ornl. gov/epubs/ndp/ ushen/newushen.html.

Zarco-Tejada, P.J., González-Dugo, V., and Berni, J.A. (2012). Fluorescence, temperature and narrow-band indices acquired from a UAV platform for water stress detection using a micro-hyperspectral imager and a thermal camera. Remote Sens. Environ. 117, 322-337. https://doi.org/10.1016/j.rse.2011.10.007

Zhang, H., Sun, K., and Li, W. (2014). Object-oriented shadow detection and removal from urban high-resolution remote sensing images. IEEE Trans. Geosci. Remote Sens. 52, 6972-6982. https: //doi.org/10.1109/TGRS.2014.2306233 